\title{
Identifikasi Struktur Bawah Tanah di Kelurahan Pangmilang Kecamatan Singkawang Selatan Menggunakan Metode Geolistrik Resistivitas dan Inversi Lavenberg - Marquardt
}

\author{
Yudha Arman 1) \\ 1) Jurusan Fisika, FMIPA Universitas Tanjungpura \\ Email : yudhaarman@gmail.com
}

\begin{abstract}
Abstrak
Telah dilakukan penelitian untuk mengidentifikasi struktur bawah permukaan di Kelurahan Pangmilang, Kecamatan Singkawang Selatan. Metode yang digunakan adalah metode geolistrik resistivitas konfigurasi Schlumberger dikombinasikan dengan metode Inversi LavenbergMarquardt. Berdasarkan perhitungan geofisika dan analisa kondisi geologi, diperoleh kondisi struktur tak selaras. Batuan jenis kuarsa aneka bahan mendominasi daerah pengukuran. Pada titik pengukuran $60 \mathrm{~m}$ dan $100 \mathrm{~m}$ terdapat bongkahan granit porphyry dengan kandungan air sebesar $\pm 0,31 \%$. Secara umum, jenis formasi granodiorit Mensibau ini terisi $0,47 \%$ air dari total luas formasi.
\end{abstract}

Kata kunci : resistivitas, Schlumberger, Lavenberg-Marquardt.

\begin{abstract}
The research to determine the subsurface structure at Kelurahan Pangmilang, Kecamatan Singkawang Selatan has been done. Resistivity method with Schlumberger electrode's configuration combined with Lavenberg-Marquardt inversion method is used. From the geophysical calculation and geological analysis, it can be seen that geological strucuture of uncorformity is found. Quartz with various kind of material dominated the location of research. There are lumped granitic porphyry's at point $60 \mathrm{~m}$ and $100 \mathrm{~m}$ which has water percentage about $0,31 \%$. In general, granodiorite Mensibau's formation has $0.47 \%$ of water from overall area of formation.
\end{abstract}

Keywords : resistivity, Schlumberger, Lavenberg-Marquardt.

\section{Pendahuluan}

Kelurahan Pangmilang, Kecamatan Singkawang Selatan adalah daerah yang diperuntukkan sebagai lokasi transmigrasi oleh pemerintah Kota Singkawang. Sebagai upaya dalam menyiapkan infrastruktur untuk maksud tersebut, dilakukan survey kelayakan lokasi, terutama survey kondisi geologi bawah permukaan. Informasi ini secara umum dapat diperoleh melalui instansi pemerintah terkait, salah satunya adalah dinas Energi dan Sumber Daya Mineral. Namun, untuk mendapatkan informasi yang lebih rinci mengenai kondisi geologi daerah setempat diperlukan survey lanjutan. Survey ini dapat dilakukan dengan menggunakan berbagai metode, baik yang bersifat destructive maupun nondestructive.

Metode geolistrik resistivitas adalah metode geofisika nondestructive yang digunakan untuk menentukan struktur bawah permukaan berdasarkan sifat tahanan jenis batuan. Metode ini telah banyak digunakan pada penentuan struktur pondasi bangunan, pendugaan potensi air bawah permukaan, eksplorasi panas bumi, eksplorasi mineral, hingga pendugaan intrusi air laut dan limbah. Data yang diperoleh dari hasil pengukuran adalah data akumulasi kondisi bawah permukaan. Pemodelan geofisika dilakukan pada data untuk memperkirakan distribusi sifat fisis bawah permukaan berdasarkan data yang diukur di permukaan bumi. Pada pemodelan inversi dicari model optimum yang berasosiasi dengan minimum suatu fungsi obyektif. Pada umumnya fungsi obyektif merupakan selisih kuadratik respons model dengan data observasi.

Pada penelitian ini dilakukan pemodelan struktur bawah permukaan untuk kemudian divalidasi dengan data hasil pengukuran. Model dibuat dan divalidasi menggunakan metode elemen hingga dan metode inversi. Model yang dihasilkan kemudian dianalisa secara geologi. Pada saat pengukuran dipilih konfigurasi elektroda Schlumber untuk mengetahui struktur bawah permukaan baik secara lateral maupun vertikal. 


\section{Tinjauan Pustaka}

\subsection{Sifat Kelistrikan Batuan}

Aliran arus listrik di dalam batuan dan mineral dapat digolongkan menjadi tiga, yaitu konduksi secara elektronik, konduksi secara elektrolitik, dan konduksi secara dielektrik. [1]

(1) Konduksi secara elektronik

Konduksi ini terjadi jika batuan atau mineral mempunyai banyak elektron bebas sehingga arus listrik dialirkan dalam batuan atau mineral oleh elektron-elektron bebas tersebut.

(2) Konduksi secara elektrolitik

Sebagian besar batuan merupakan konduktor yang buruk dan memiliki resistivitas yang sangat tinggi. Batuan biasanya bersifat porous dan memiliki pori-pori yang terisi oleh fluida, terutama air. Batuan-batuan tersebut menjadi konduktor elektrolitik, dimana konduksi arus listrik dibawa oleh ionion elektrolitik dalam air. Konduktivitas dan resistivitas batuan bergantung pada volume dan susunan pori-porinya. Konduktivitas akan semakin besar jika kandungan air dalam batuan bertambah banyak, dan sebaliknya resistivitas akan semakin besar jika kandungan air dalam batuan berkurang.

(3) Konduksi secara dielektrik

Konduksi pada batuan atau mineral bersifat dielektrik terhadap aliran listrik, artinya batuan atau mineral tersebut mempunyai sedikit elektron bebas, bahkan tidak ada sama sekali. Tetapi karena adanya pengaruh medan listrik dari luar maka elektron dalam bahan berpindah dan berkumpul terpisah dari inti, sehingga terjadi polarisasi.

\subsection{Geolistrik Resistivitas}

Survey geolistrik (resistivitas) pada umumnya bertujuan untuk mengetahui kondisi atau struktur geologi bawah permukaan berdasarkan variasi tahanan jenis batuannya.[2] Struktur geologi yang dapat dideteksi dengan metode ini terutama adalah yang mempunyai kontras tahanan jenis yang cukup jelas terhadap sekitarnya, misalnya untuk keperluan eksplorasi air tanah, mineral, geothermal (panasbumi). Prinsip pelaksanaan survey geolistrik adalah dengan menginjeksikan arus listrik melalui elektroda arus dan mengukur responnya (tegangan) pada elektroda potensial dalam suatu susunan (konfigurasi) tertentu. ${ }^{[3]}$
Berdasarkan tujuan dan cara pengubahan jarak elektroda, survey geofisika dibagi menjadi dua cara, yaitu mapping dan sounding. Mapping dimaksudkan untuk mengetahui variasi horizontal atau lateral tahanan jenis batuan pada kedalaman tertentu. Jarak antar elektroda dibuat tetap sesuai dengan kedalaman daya penetrasi yang diinginkan, selanjutnya seluruh susunan elektroda dipindahkan menurut suatu lintasan tertentu. Sedangkan sounding dimaksudkan untuk mengetahui variasi tahanan jenis batuan terhadap kedalaman (secara vertikal). Jarak antar elektroda diperbesar dalam suatu arah bentangan pada suatu titik tertentu.[4]

\subsection{Konfigurasi Schlumberger}

Konfigurasi elektroda Schlumberger bertujuan untuk mengidentifikasi diskontinuitas lateral dan vertikal (anomali konduktif lokal). Arus diinjeksikan melalui elektroda $A B$, dan pengukuran beda potensial dilakukan pada elektroda MN [1], dimana jarak elektroda arus (AB) jauh lebih besar dari jarak elektroda tegangan (MN). Pengukuran dengan konfigurasi Schlumberger yang menggunakan empat elektroda, masing-masing dua elektroda arus dan dua elektroda tegangan ini ditunjukkan oleh gambar 1 .

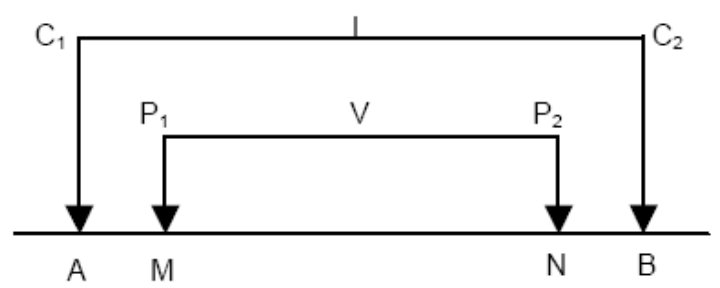

Gambar 1. Konfigurasi Schlumberger [5]

Tahanan jenis semu medium yang terukur dihitung berdasarkan persamaan [1] [5]

$$
\rho=K \frac{\Delta V}{I}
$$

dengan

$\mathrm{K}=2 \pi\left\{\left(\frac{1}{A M}-\frac{1}{B M}\right)-\left(\frac{1}{A N}-\frac{1}{B N}\right)\right\}^{-1}$,

MN adalah spasi elektroda potensial, AM dan NB adalah kelipatan bulat spasi elektroda (n.a), dan $\mathrm{MB}=\mathrm{AN}=\mathrm{a}(\mathrm{n}+1)$. Untuk konfigurasi Schlumberger, variabel $\mathrm{K}$ dapat juga dihitung menggunakan persamaan :

$K=n(n+1) \pi a, n=1,2,3, \ldots$ 
dengan $\rho$ adalah tahanan terukur (apparent resistivity), $\Delta \mathrm{V}$ adalah potensial yang terukur antara elektroda $\mathrm{P}_{1}$ dan $\mathrm{P}_{2}$, I adalah arus listrik yang mengalir ke tanah melalui elektroda $\mathrm{C}_{1}$ dan $\mathrm{C}_{2}$, dan $\mathrm{K}$ adalah faktor geometri konfigurasi elektroda.

\subsection{Inversi Kuadrat Terkecil}

Nilai resistivitas yang diperoleh pada pengambilan data bukanlah merupakan data resistivitas yang sebenarnya. Untuk menghasilkan data resistivitas yang sebenarnya diperlukan memecahkan solusi persamaan berikut: [6]

$$
\begin{aligned}
& -\nabla \cdot[\sigma(x, y, z) \nabla \phi(x, y, z)]= \\
& \left(\frac{I}{\Delta V}\right) \delta\left(x-x_{s}\right) \delta\left(y-y_{s}\right) \delta\left(z-z_{s}\right)
\end{aligned}
$$

dengan $\sigma$ adalah konduktivitas medium, $\phi$ adalah potensial listrik, $\Delta \mathrm{V}$ adalah elemen volume di sekitar sumber arus (I) yang berada pada posisi $\left(\mathrm{x}_{\mathrm{s}}, \mathrm{y}_{\mathrm{s}}, \mathrm{z}_{\mathrm{s}}\right)$ dan $\delta$ adalah delta Dirac.

Persamaan (4) dapat diselesaikan secara numerik menggunakan metode beda hingga dan elemen hingga. Persamaan ini merupakan pemodelan ke depan yang membuat parameter model menjadi model. Terlihat dari persamaan (4) hubungan antara parameter model dan peubah bebas adalah tak linier.

Dalam permasalahan nonlinier, hubungan antara data hasil pengukuran (d) dengan parameter model (m) melalui suatu fungsi nonlinier pemodelan ke depan (g) adalah: ${ }^{[7]}$

$$
\mathbf{d}=\mathbf{g}(\mathbf{m})+\mathbf{e}
$$

dengan e adalah vektor kesalahan atau noise. Untuk mendapatkan model bumi yang responsnya merepresentasikan data hasil pengukuran, dilakukan minimalisasi kuadrat kesalahan dengan bentuk persamaan sebagai berikut :

$$
\mathbf{E}=\mathbf{e}^{\mathrm{T}} \mathbf{e}=[\mathbf{d}-\mathbf{g}(\mathbf{m})]^{\mathrm{T}}[\mathbf{d}-\mathbf{g}(\mathbf{m})]
$$

dengan $\mathbf{e}^{\mathrm{T}}$ adalah transpose dari e. Metode ini dapat digunakan secara iteratif dan merupakan permasalahan yang didekati secara linier untuk mendapatkan tebakan model awal [8]. Jika diasumsikan bahwa model adalah linier dengan tebakan awal $\mathbf{m}_{0}$, ekspansi deret Taylor yang dibatasi pada orde pertama di sekitar $\mathbf{m}_{0}$ adalah:

$$
\mathbf{g}(\mathbf{m}) \cong \mathbf{g}\left(\mathbf{m}_{\mathbf{0}}\right)+\frac{\partial \mathbf{g}\left(\mathbf{m}_{\mathbf{0}}\right)}{\partial \mathbf{m}}\left[\mathbf{m}-\mathbf{m}_{0}\right]
$$

$$
\mathbf{g}(\mathbf{m}) \cong \mathbf{g}\left(\mathbf{m}_{\mathbf{0}}\right)+\mathbf{J} \Delta \mathbf{m}
$$

dengan J adalah matriks Jacobian (turunan parsial pemodelan ke depan terhadap parameter model) dan $\Delta \mathbf{m}$ adalah vektor yang berisi koreksi parameter atau perturbasi model. Persamaan (6) kemudian dapat dituliskan sebagai :

$$
\mathbf{E}=[\Delta \mathbf{d}-\mathbf{J} \Delta \mathbf{m}]^{\mathbf{T}}[\Delta \mathbf{d}-\mathbf{J} \Delta \mathbf{m}]
$$

dengan vektor $\Delta \mathbf{d}$ adalah vektor selisih antara respon hasil pengukuran dengan hasil perhitungan pada $\mathbf{m}_{0}$. Dengan melakukan minimisasi E akan diperoleh koreksi parameter :

$$
\Delta \mathbf{m}=\left[\mathbf{J}^{\mathrm{T}} \mathbf{J}\right]^{-1} \mathbf{J}^{\mathrm{T}} \Delta \mathbf{d}
$$

yang dikenal dengan solusi Gauss-Newton. Untuk menghindari matriks [ $\left.\mathbf{J}^{\mathrm{T}} \mathrm{J}\right]$ mendekati singular, dilakukan pengontrolan panjang langkah pada koreksi $\Delta \mathbf{m}$ dengan memasukkan sebuah konstrain pada persamaan (9) sehingga dapat dituliskan :

$$
\begin{gathered}
\mathbf{E}=[\Delta \mathbf{d}-\mathbf{J} \Delta \mathbf{m}]^{\mathbf{T}}[\Delta \mathbf{d}-\mathbf{J} \Delta \mathbf{m}] \\
+\beta\left[\Delta \mathbf{m}^{\mathrm{T}} \Delta \mathbf{m}-\mathrm{L}^{2}\right]
\end{gathered}
$$

dengan $\mathrm{L}^{2}$ adalah suatu kuantitas tertentu yang membatasi energi elemen-elemen pada koreksi parameter $\Delta \mathbf{m}$ dan $\beta$ adalah faktor damping. Dengan melakukan minimisasi E terhadap $\mathbf{m}$ diperoleh persamaan koreksi parameter sebagai berikut :

$$
\Delta \mathbf{m}=\left[\mathbf{J}^{\mathrm{T}} \mathbf{J}+\beta \mathbf{I}\right]^{-1} \mathbf{J}^{\mathrm{T}} \Delta \mathbf{d}
$$

Dalam bentuk iteratif dapat dituliskan sebagai: [9]

$$
\mathbf{m}_{\mathrm{k}+1}=\mathbf{m}_{\mathrm{k}}+\left[\mathbf{J}^{\mathrm{T}} \mathbf{J}+\beta \mathbf{I}\right]^{-\mathbf{1}} \mathbf{J}^{\mathrm{T}} \Delta \mathbf{d}
$$

yang kemudian dikenal dengan solusi Lavenberg-Marquardt. 


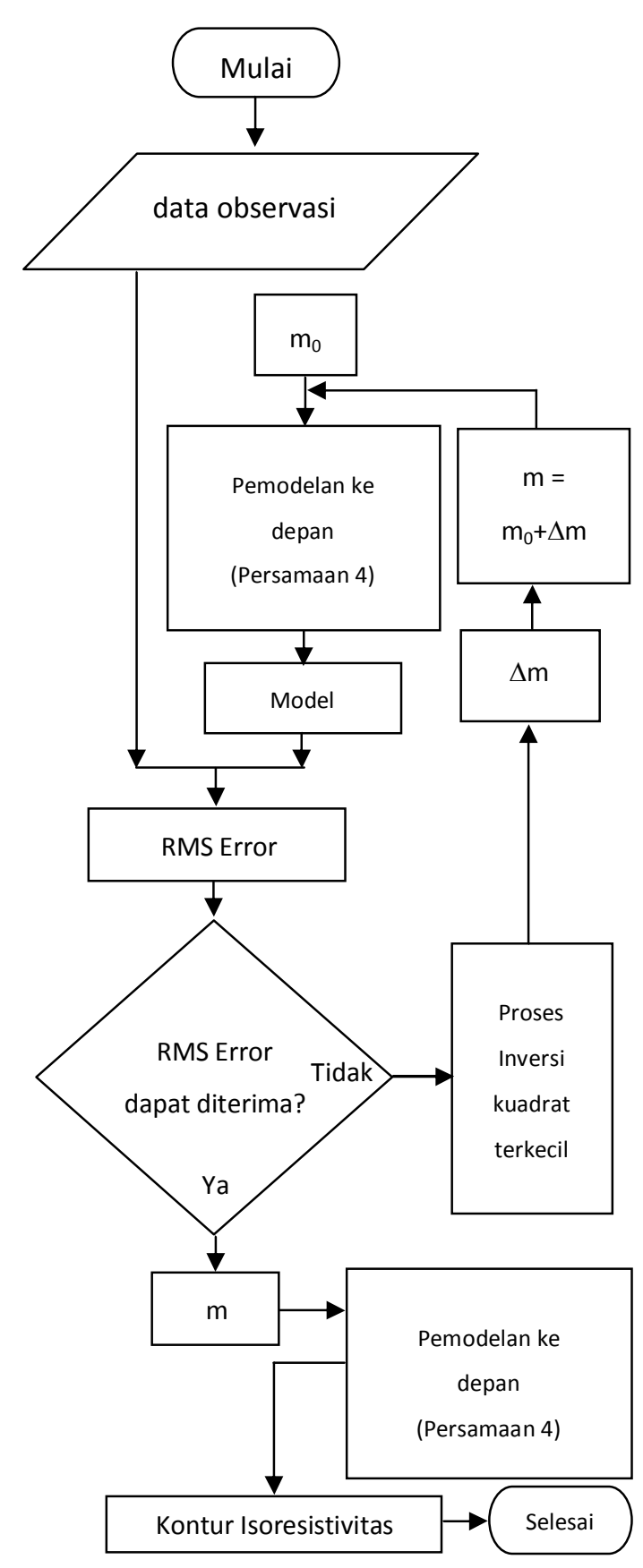

Gambar 2. Diagram alir pengolahan data

\section{Hasil Dan Pembahasan}

Lokasi penelitian berada pada koordinat N $00^{0} 47^{\prime}$ 54,6 “, E $109^{0} 02^{\prime}$ 33,1 “ dengan topografi yang relatif datar. Lokasi ini juga terdapat sumber air bersih permukaan. Sumber air ini terletak $\pm 2 \mathrm{~km}$ dari jalan raya Sagatani.

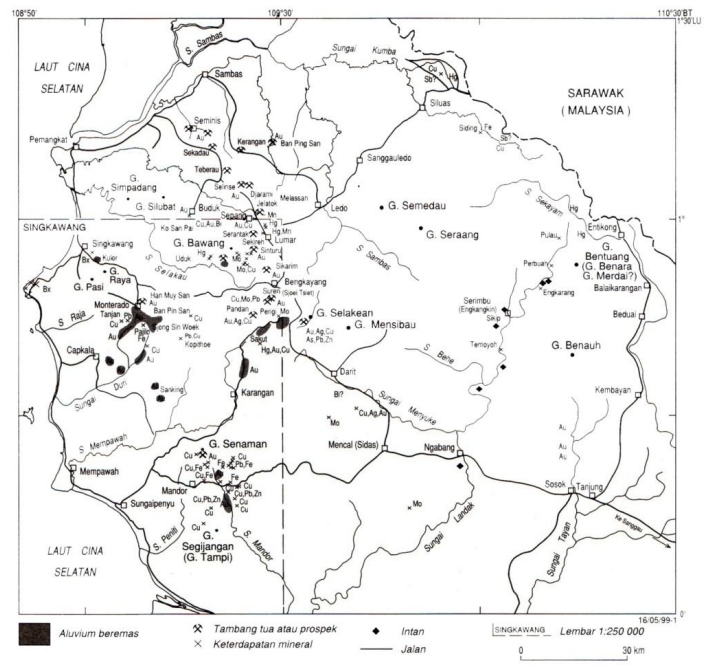

Gambar 3. Peta lokasi penelitian [10]

Secara geologi, lokasi ini didominasi oleh satuan litologi granodiorit Mensibau, terutama granodiorit dengan granit, diorit kuarsa, diorit, adamelit dan tonalit. Endapan ini diperkirakan diendapkan pada masa kapur bawah (Lower Cretaceous). Formasi ini terdiri dari: [10]

(1) Granodiorit hornblenda-biotit, adamelit, tonalit, granodiorit biotit-hornblenda, diorit, diorit kuarsa, granit, memiliki sifat magnetik sedang sampai kuat, umumnya terubah, setempat tergeruskan kuat, termilonitkan, dan terbreksikan, terdapat senolit batuan Gunung api sedimen.

(2) Granodiorit lekokratik yang merupakan fenokris plagioklas, kuarsa sampai $4 \mathrm{~mm}$ dan senolit bauan Gunung api Raya.

(3) Granodiorit hornblenda-biotit, lekokratik-mesokratik, dengan ciri berbutir sedang-seragam sampai diorit kuarsa dan tonalit.

(4) Granodiorit biotit-hornblenda, berbutir kasar, fenokris plagioklas, kuarsa, biotit dan hornblenda sampai $3 \mathrm{~mm}$ di dalam masa dasar yang sama, banyak terdapat senolit dari batuan Gunung api Raya.

(5) Diorit kuarsa, yaitu mesokratik dengan tekstur halus sampai sedang, holokristalin, kuarsa plagioklas, hornblenda, sedikit augit dan piroksenorto.

(6) Granit, granit biotit merah jambu lekokratik sampai adamelit, cenderung merupakan kerabat termuda.

Struktur perlapisan formasi ini menerobos Kelurahan Bengkayang dan batuan Gunung api Raya, diterobos oleh dasit Bawang dan batuan terobosan Sintang, tidak selaras di bawah formasi Hamisan, setara 
dengan diorit kuarsa Tiang, granodiorit Gunung Sebiawak, Gunung Raya dan Gunung Selanatar, serta granit lainnya yang tak berama, serta batuan terobosan tua.

Target lokasi kedalaman penetrasi arus bagi survey geolistrik ini adalah $\pm 25 \mathrm{~m}$ dengan bentangan elektroda terjauh sebesar $140 \mathrm{~m}$. Survey dilaksanakan dengan orientasi bentangan elektroda A ke elektroda 0 pada $32,5^{\circ}$ Barat Laut ke 13,50 Tenggara.

Data yang diperoleh kemudian diolah dengan bantuan perangkat lunak Res2DInv. Parameter parameter damping yang digunakan memiliki nilai minimum 0,015 yang dibuat berubah terhadap iterasi. Perhitungan pemodelan ke depan menggunakan metode elemen hingga untuk memecahkan persamaan (4).

Untuk memperoleh akar kuadrat sebesar 5,8 \%, diperlukan lima iterasi pada proses inversi Lavenberg Marquardt. Faktor damping digunakan pada program dengan nilai yang berubah-ubah. Optimasi faktor damping dilakukan dengan bantuan algoritma yang terdapat pada perangkat lunak Res2DInv.

Dari hasil pengolahan data terlihat sebaran nilai resistivitas yang besar (hingga $\pm 8100 \Omega \mathrm{m}$ ) karena lokasi ini didominasi oleh batuan beku berupa granitan. Air yang terdapat pada batuan pasir dan kerikil hasil sedimentasi batuan beku ini tersebar tidak merata dan berada tidak terlalu dalam. Batuan beku jenis kuarsa aneka bahan juga mendominasi daerah pengukuran. Pada titik pengukuran $60 \mathrm{~m}$ dan $100 \mathrm{~m}$ terdapat bongkahan granit porphyry dengan kandungan air sebesar $\pm 0,31 \%$. Dari keseluruhan interpretasi data ini menunjukkan bahwa lokasi ini minim sumber air bawah tanah. Keberadaan air bawah tanah diduga hanya terisi pada pori dari batuan pasir dengan nilai resistivitas 0 hingga $500 \Omega \mathrm{m}$. Secara umum, jenis formasi Granodiorit Mensibau ini terisi 0,47 \% air dari total luas formasi. [10]

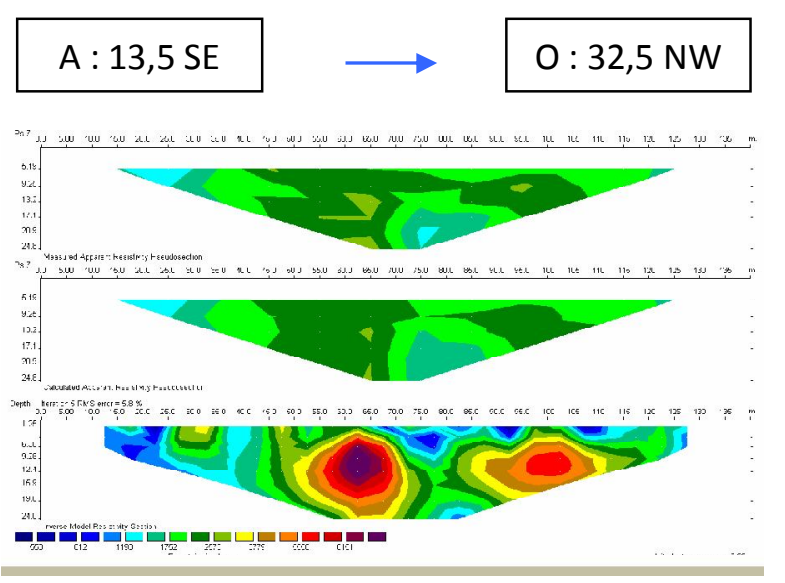

Gambar 4. Hasil pengolahan data menggunakan perangkat lunak Res2DInv

\section{Kesimpulan}

Pemodelan ke depan geofisika dikombinasikan dengan pemodelan inversi dilakukan untuk menghasilkan model kondisi geologi bawah permukaan. Dihasilkan rms error sebesar 5,8 \% untuk lima iterasi. Dari hasil pengolahan data terlihat sebaran nilai resistivitas yang besar (hingga $\pm 8100 \Omega \mathrm{m}$ ) karena lokasi ini didominasi oleh batuan beku berupa granitan dan juga batuan beku jenis kuarsa aneka bahan. Pada titik pengukuran $60 \mathrm{~m}$ dan $100 \mathrm{~m}$ terdapat bongkahan granit porphyry dengan kandungan air sebesar \pm $0,31 \%$. Dari keseluruhan interpretasi data ini menunjukkan bahwa lokasi ini minim sumber air bawah tanah. Keberadaan air bawah tanah diduga hanya terisi pada pori dari batuan pasir dengan nilai resistivitas 0 hingga $500 \Omega \mathrm{m}$.

\section{Daftar Pustaka}

[1] Telford, W M., Geldart L.P.,Sheriff R.R., 1990, Applied Geophysics $2^{\text {nd }}$ Edition, Cambridge University Press, Cambridge

[2] Grandis, H., 1986, Penerapan Metode Gaya Berat dan Tahanan Jenis Dalam Eksplorasi Pendahuluan Daerah Prospek Panasbumi, Tugas Akhir Jurusan GM -ITB.

[3] Hochstein M.P., 1982, Introduction to Geothermal Prospecting, Geothermal Institut, University of Auckland

[4] Koefoed, O.,1979,Geosounding Principles : Resistivity Sounding Measurement, Elsevier. 
[5] Reynolds, J.M. 1998. An Introduction to Applied and Environmental Geophysics. New York: John Willey and Sons.

[6] Dey, A., dan Morrison. H. F., 1979, Resistivity Modelling For Arbitrary Shaped Two-Dimensional Structures, Geophysical Prospecting, V. 27, p. 1020-1036

[7] Menke, W., 1984, Geophysical Data Analysis : Discrete Inverse Theory, Academic Press. Inc., Orlando-Florida.

[8] Lines, L. R., dan Treitel. S., 1984, Tutorial : A Review of Least Squares Inversion And Its Application To Geophysical Problems, Geophysical Prospecting, V.47, no. 1, p.159-186.

[9] Grandis, H., 2009, Pengantar Pemodelan Inversi Geofisika, Himpunan Ahli Geofisika (HAGI), Bandung.

[10] Suwarna, N., 1993, Geologi Lembar Singkawang, Kalimantan, Departemen Pertambangan dan Energi, Direktorat Jenderal Geologi dan Sumberdaya Mineral, Pusat Penelitian dan Pengembangan Geologi, Bandung. 